\title{
PENILE FRACTURE-REPORT OF TWO CASES AND REVIEW OF CURRENT LITERATURES
}

\author{
ASHRAF UDDIN MALLIK ${ }^{1}$, MD TAREQUE HASAN ${ }^{2}$, HOROBILASH HALDER ${ }^{3}$
}

${ }^{1}$ Department of Urology, Gonoshasthaya Samajvittik Medical College (GSMC), Nalam, Savar, Dhaka, ${ }^{2}$ Department of Surgery, GSMC, Nalam, Savar, Dhaka, ${ }^{3}$ Department of Anaesthesiology, GSMC, Savar, Dhaka

\begin{abstract}
Penile fracture is an uncommon urological emergency especially in Bangladesh. The other name is traumatic rupture of the tunica albugenia and corpora cavernosa in erect penis. It occurs when an erect penis face to buckle under the pressure of a blunt sexual trauma. Patient gives the typical history of immediate detumescence, severe pain, swelling and eggplant deformity of the penile shaft due to penile injury. Immediate surgical exploration and repair of corpora Cavernosa with tunica albugenia is the most effective treatment modality. In normal cases diagnosis is made from history, physical examination alone. In some special cases ultrasonogram, radiological images, including retrograde urethrography or cavernosography are mandatory for proper diagnosis. Herein, we report 2 cases of penile fracture with review of current literature regarding treatment options.
\end{abstract}

Key words: Cavernosography, Penile fracture, Tunica Albugenia rupture, Urethrography.

Bangladesh J. Urol. 2016; 19(2): 98-102

\section{Introduction:}

Penile fracture is rupture of one or both of the tunica albuginea, the fibrous coverings that envelop the penis's corpora cavernosa. During vaginal or anal intercourse, or aggressive masturbation it is caused by rapid blunt force to an erect penis[1]. Partial or complete rupture of the urethra or injury to the dorsal nerves, veins and arteries are sometimes involve[2]. It is an urological emergency that always deems attention[3]. Although penile fracture is easily recognized and therefore classified as a "first-look diagnosis," this clinical entity is always embarrassing for patients as well as partners and goes unreported many times 4 . Eminently it is an entity of clinical diagnosis[5]. Therefore the management of a penile fracture should notinclude any further investigation rather than surgical exploration. The need for immediate surgery is emphasized, in order to avoid erectile failure and curvature. Many conditions can simulate fracture penis as dorsal vein tears $[6,7,8]$. Authors reviewed the literatures of penile fracture and reported two cases of 21 and 50-year-old men who presented with egg-plantdeformity of penile shaft and

Correspondences: Dr. Ashraf Uddin Mallik, Department of Urology, Gonoshasthaya Samajvittik Medical College, Nalam, Savar, Dhaka, E-mail: ashrafmallik143@gmail.com discoloration of penile skin and swelling penis after cracking sound during forceful bending of penile shaft followed by severe pain at the time of fracture. The main aim of this study was to describe treatment option of 2 patients with fracture penis in our urology department and reviewed of literatures.

\section{Case 1}

We report the case of a 21-year-old unmarried student who presented to the emergency department few hours following blunt injury of the penis during forceful bending of erect penis. The patient reported a "tearing/popping" sensation, rapid detumescence, severe penile pain and no blood per urethra, after erection in morning when he tried to bend the penis by himself. The patient was able to void without any voiding sensation, following the injury. On physical examination the penis was found swollen, discoloration of penile skin, scrotum and part of perineum. eggplant deformity of penile shaft. Figure 1 shows eggplant deformity of penile shaft. "Rolling sign" was present bilaterally, palpated at the sites of tunica albugenia disruption about $1 \mathrm{~cm}$ from the base of the penis and the penis was not tender on examination. Clinically diagnosed as penile fracture. 


\section{Case 2}

A 50-year-old married business male presented with a history of bending of his penis during vigorous coitus with his wife after taking an erotic stimulant drug at 12.30 night. During coitus he felt sudden thrust with body of his wife followed by cracking sound, sudden detumescence, swelling and deformity of penis, scrotum. On physical examination, penis was swollen, discoloration of penile skin, eggplant deformity of penis and "Rolling sign" was present. On the basis of his clinical presentation a diagnosis of penile fracture was made. A penile catheter of $16 \mathrm{~F}$ was inserted per urethra to serve as stent Vital signs were normal. Pathological examinations like CBC, BT,CT, S.creatinine, RBS were done. Immediate surgical exploration and repair of rupture tunica albugenia and corpora cavernosa was done under spinal anesthesia. In both cases a sub coronal circumscribes degloving incision was given. A tear in tunica albugenia and corpora cavernos was found on left side and $2 \mathrm{~cm}$ distal to the root of the penis and there was blood clot. Repair of corpora cavernosa and tunica albugenia with sutures of vicryl 2-0 was performed after removing the clot (Figure 2). Post-operatively patient was prescribed antibiotics, analgesic and the urethral catheter was kept for 10 days, which was subsequently removed before discharge (Figure 3 ). Both of them were asked to abstain from masturbation or intercourse until complete healing occurred. At 3 months interval the optimal voiding function, erection function and cosmetic result were achieved in one case and in other case urethral stricture developed, which was repaired successfully after 4 months with end to end anastomosis. Based on our experience, this management approach results an excellent preservation of both penile anatomy and function.

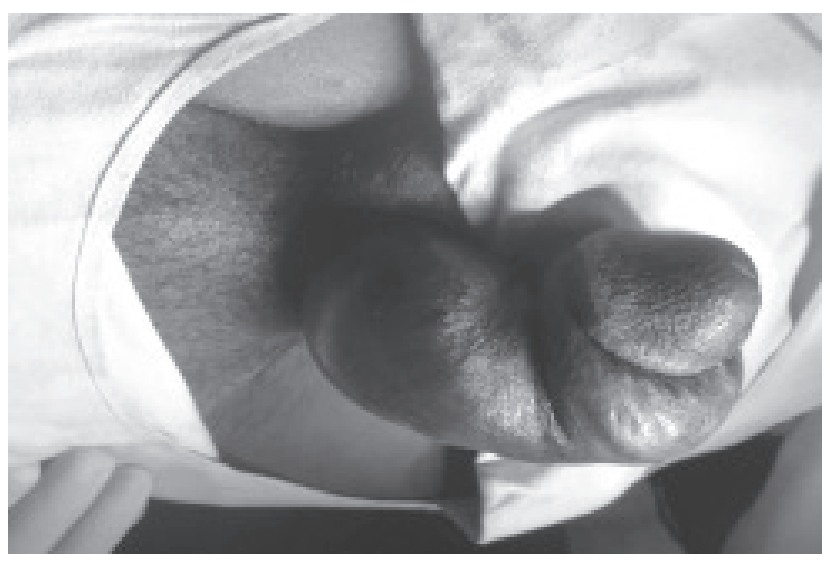

Fig.-1: Eggplant deformity of penile shaft after penile fracture

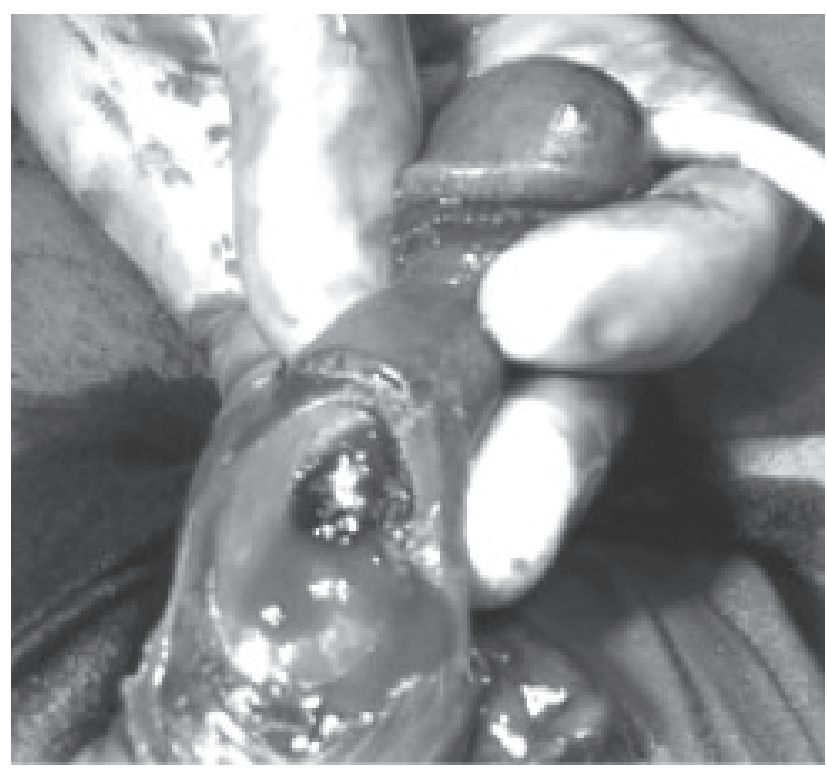

Fig.-2: Fracture of Tunica Albugenia and Corpora Cavernosa

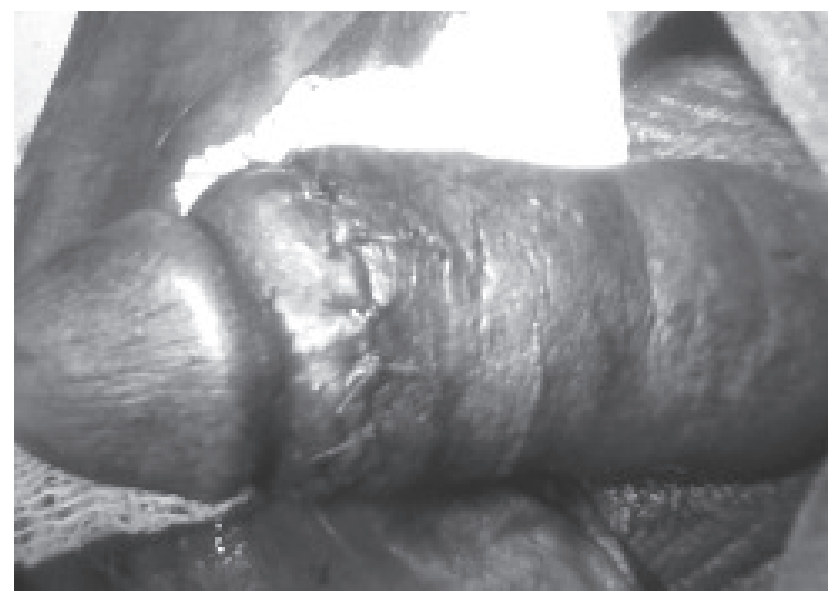

Fig.-3 : Just after repair of penile fracture

\section{Discussion}

Penile fracture is a rare urologic emergency condition that affects all social strata. It has an incidence of 1 in 175,000 admissions and is commoner in countries where there is segregation of the sexes for social and religious reasons, where its etiologic factor is mostly from self manipulation $[9,10]$. Mechanism of fracture: During an erection, the penis is engorged with blood. If the penis is bent suddenly or forcefully while it's engorged, the trauma may rupture tunica albugeinea, the lining of corpora cavernosa responsible for erections - resulting penile fracture. As the penis changes from a flaccid state to an erect state, the thick tunica albugenia becomes very thin. The tunica albugenia is the fibrous 
covering of the penile corpora cavernosa and is directly involved in maintaining an erection. During erection it thins from $2 \mathrm{~mm}$ to $0.25-0.5 \mathrm{~mm}$, stiffens and becomes less elastic and easily fracturable. Sudden direct trauma or abnormal bending in erect state causes tearing of the tunica albugenia, usually in transversal direction, rarely oblique or irregular[5]. Penile fractures have been classified as simple and compound[11]. Simple penile fractures are those with intact skin and urethra while those with urethral rupture are compound. One patients treated in our department had simple fractures another was compound fracture involving the urethra which was reported later having urethral stricture that was corrected surgically.. oncomitant urethral injury occurs in about $10-58 \%$ of cases[12]. Associated urethral rupture is seen more in coital fractures than those following manipulations that was found in our one case also[11]. The predisposing factor to concomitant urethral injury in penile fracture is not clear but it is postulated to be due to a more vigorous force applied during coitus compared with the prolonged but lesser force involved in masturbation[11,13]. Penile fracture may present with classic "eggplant deformity" of swollen penis along with ecchymosis confined to Buck's fascia[11]. The patient usually describe a cracking or popping sound during injury as tunica tears, followed by pain, rapid detumescence, discoloration and swelling of penile shaft $[1,2,3]$. Fracture typically occurs during vigorous sexual inter-course, when the erect penis slips out of the vagina and strikes the perineum or pubic bone, Other causes may be masturbation with or without devices. It can happen from any type of blunt trauma affecting the tumescent shaft. Falling out of bed with an erection, extreme sexual activity, especially during coitus in which the female is on top, forceful correction of a congenital chordee and even tucking an erect penis into underwear. In the Middle East self inflicted fractures predominate. Taqaandan also a cause of penile fracture. It comes from a Kurdish word meaning "to click," involves bending the top part of the erect penis while holding the lower part of the shaft in place, until a click is heard and felt.

Penile fracture can usually be diagnosed based solely on history and physical examination findings. Sometimes in complicated cases, and to find out associated injury ultrasonogram, urethrogram, cavernosogram, MRI should be performed. Because of fear and embarrassment the patient present to health care professional sometimes significantly in delay. But in our case both the victim gave detail history when we asked.
False fracture penis has been reported in literature, who presented with penile swelling and echymosis. In those case they did not describe classic"snap-pop" or rapid detumescence"egg-plant" deformity of the shaft, whose features are associated with fracture penis. Physical examination may not be adequate for confirm diagnosis. Dorsal penile artery or vein injury during sexual intercourse, mimic penile fracture. Lacerations of the corpus cavernosa from gunshot and sporting injuries to the flaccid penis are not considered as penile fractures since they lack the fulcrum for snapping[12]. In western countries upto $50 \%$ of penile fracture occurs during vigorous intercourse. Other causes include industrial accidents, masturbation, gunshot wound or other mechanical trauma that causing forceful breaking of an erect penis.In Middle East the injuries occurs due to penile manipulation to achieve detumescence. Another causes are turning over in bed, a direct blow or forceful bending of penis. In Nigeria reported causes of fracture are masturbation, stuttering priapism, vigorous sexual intercourse, turning in bed, forceful bending in erect penis by locally made bamboo bed[13]. Recent finding indicate that penile fracture appear to be in those population who use sexual xciting drugs before sexual intercourse. The case reported above was having coitus with wife sing sexual stimulant drugs and another was masturbation.

Treatment may be either conservative or surgical. The conservative management of penile fracture includes splinting, cold compresses, and a combination of antiinflammatory, analgesic medications and fibrinolytics. In our 2 cases we did surgical exploration immediately after fracture and repaired. This concept has fallen into disfavor because of the high complication rates (29-53\%) of nonoperative therapy[14].

Commonly complications encountered following conservative management as reported in literatures are penile angulation, painful erection and coitus, $A-V$ fistula, infected hematoma, abscess formation and impotance[3]. For these complications immediate surgical intervention is advocated as we did in our cases[15]. The goal of immediate surgical correction to the fracture penis are restoration of penis to its preinjur state, prevent erectile dysfunction, maintain penile length and allow normal voiding[3]. It causes short term hospital stay, patient satisfaction, safe from penile deformity development and erectile dysfunction. Ideal management of penile fracture include identification of proper injury site, evacuation of hematoma, removal of corporal 
debridement, properly closure of tunica albugenia, corpora and ligation of any bleeding vessels [16]. Three types of incisions are advocated in literatures: direct incision over corpus cavernosum causes minimal dissection of the neurovascular bundles, less trauma and even local anesthesia can be used but it does not allow complete repair. Some did repair with general anesthesia, but in our cases we did repair with spinal anesthesia and achieved good result. There was no impaired penile sensation or distal skin necrosis as described by others. That's why sub-coronal incision with spinal anesthesia appears to be satisfactory than other incisions. Treatment options for partial urethral tears include urethral catheterization, primary closure with nonabsorbable suture, or suprapubic cystostomy tube.

Penile fracture is a urologic emergency that may have devastating physiologic and psychologic consequences. However, with prompt diagnosis and expedient surgical management, outcomes remain excellent and complications are minimal[17,18,19].

\section{Conclusion}

The diagnosis of penile fracture is mostly a clinical one. Prompt surgical exploration and repair are advocated in almost all cases. Most commonly, the rupture occurs on the lateral side of the proximal corpora, but it can occur anywhere along the corpora and produce a variety of swelling patterns. Hematuria and voiding symptoms are not specific to a urethral injury. Their presence should prompt the performance of retrograde urethrography. Corporal cavernosography might aid in localizing an unusual injury prior to surgery; however, the procedure is limited by technical requirements and the possibility of false-negative results. Immediate surgery reduces long-term complications; posttraumatic penile curvature remains the most common long-term complaint.

\section{Learning points}

- Fracture of has a typical history with special clinical findings It should be identified clinically and explore surgically as early as possible to avoid penile deformity, painful erections or erectile dysfunction.

- Complete degloving of the penile shaft should be done to locate the exact site of rupture and to repair properly.

\section{References}

1. Greenberg's Text-Atlas of Emergency Medicine. Lippincott Williams \& Wilkins. 22 November 2004. p. 318. ISBN 978-0-7817-4586-4. Retrieved 15 October 2012.

2. Haas CA, Brown SL, Spirnak JP (April 1999). "Penile fracture and testicular rupture". World $\mathrm{J}$ Urol. 17 (2): 101-6.

3. Mahapatra RS, Kundu AK, Pal DK. Penile Fracture: Our Experience in a Tertiary Care Hospital. World J Mens Health. 2015 Aug. 33 (2):95-102. [Medline].

4. Bhoil R, Sood D. Signs, symptoms and treatment of penile fracture. Emerg Nurse. 2015 Oct. 9. 23 (6):16-7. [Medline].

5. Swanson DE, Polackwich AS, Helfand BT et.al . Penile fracture: outcome of early surgical intervention. Urology. 2014 Nov ; 84(5) : 1117-21.

6. Perovic SV, Djinovic RP, Bumbasirevic MZ, Santucci RA, Djordjevic ML, Kourbatov D. Severe penile injuries: a problem of severity and reconstruction. BJU Int. 2009 Jan 20. [Medline].

7. Ghilan AM, Al-Asbahi WA, Ghafour MA, Alwan MA, Al-Khanbashi OM. Management of penile fractures. Saudi Med J. 2008 Oct. 29(10):1443-7. [Medline].

8. Maruschke M, Lehr C, Hakenberg OW. Traumatic penile injuries-mechanisms and treatment. Urol Int. 2008. 81(3):367-9. [Medline].

9. Rajih E, Alenizi A, El-Hakim A. Penile fracture with two epsilateral Corporal tears and delayed presentation : A case report. Can Urol Assoc J. 2015 ; Sep-Oct ; 9(9-10).

10. Majzoub AA, Canguven O,Raidh TA. Alteration in the etiology of penile fracture in the Middle East and Central Asia regions in the last decade ; a literature review. Urol Ann. 2015 July-Sep ; 7(3) : 284-8 .

11. Eke N. Fracture of the penis. Br J Surg. 2002; 89: 555-565.

12. Koifman L, Cavalcanti AG, Manes $\mathrm{CH}$ et. al. Penile fracture. Experience in 56 cases. Int. Braz J Urol 2003; 29(1):35-39.

13. Al Ansari A, Talib RA, Shamsodini A et al. Which is guilty in self-induced penile fracture,marital Status, culture or geographic region? Acase series 
and literature reviews. Int Impot Res. 2013 NovDec; 25(6):221-3.

14. Shittu OB, Kamara TB. Fracture of the penis diagnosis and management. Afr J Med Sci 2000; 29: 179-180.

15. Al-Reshaid RA, Madbouly K, Al-Jasser A. Penile abscess and necrotizing fasciitis secondary to neglected false penile fracture. Urol Ann. 2010;2:86-88. [PMC free article] [PubMed]

16. Agarwal MM, Singh SK, Sharma DK, Ranjan P, Kumar S, Chandramohan V, et al. Fracture of the penis: a radiological or clinical diagnosis? A case series and literature review. Can J Urol. 2009 Apr. 16(2):4568-75. [Medline].

17. Llarena IR, Villafruela MA, Azurmendi AJ, et al. Penile fracture with associated urethral rupture. Arch Esp Urol. 2006; 59:732-736.

18. Song W, Ko KJ, Shin SJ, Ryu DS. Penile abscess secondary to neglected penile fracture after intracavernosal vasoactive drug injection. World $\mathrm{J}$ Mens Health. 2012 Dec. 30(3):189-91.[Medline].

19. Ateyah A, Mostafa T, Nasser TA, Shaeer O, Hadi AA, Al-Gabbar MA. Penile fracture: surgical repair and late effects on erectile function. J Sex Med. 2008 Jun. 5(6):1496-502. [Medline]. 